\title{
How Experiencing Preventable Medical Problems Changed Patients' Interactions With Primary Health Care
}

\author{
Nancy C. Elder, MD, MSPH ${ }^{1}$ \\ C. Jeffrey Jacobson, $P b D^{1}$ \\ Therese Zink, MD, MPH ${ }^{2}$ \\ Lora Hasse, $\mathrm{PbD}^{3}$ \\ 'Department of Family Medicine, University \\ of Cincinnati, Cincinnati, Ohio \\ ${ }^{2}$ Department of Research, Olmstead Medical \\ Center, Rochester, Minn \\ ${ }^{3}$ Cincinnati Children's Hospital Medical \\ Center, Cincinnati, Ohio
}

\begin{abstract}
PURPOSE We wanted to explore how patients' experiences with preventable problems in primary care have changed their behavioral interactions with the health care system.

METHODS We conducted semistructured interviews with 24 primary care patients, asking them to describe their experiences with self-perceived preventable problems. We analyzed these interviews using the editing method and classified emotional and behavioral responses to experiencing preventable problems.

RESULTS Anger was the most common emotional response, followed by mistrust and resignation. We classified participants' behavioral responses into 4 categories: avoidance (eg, stop going to the doctor), accommodation (eg, learn to deal with delays), anticipation (eg, attend to details, attend to own emotions, acquire knowledge, actively communicate), and advocacy (eg, get a second opinion).
\end{abstract}

CONCLUSIONS Understanding how patients react to their experiences with preventable problems can assist health care at both the physician-patient and system levels. We propose an association of mistrust with the behaviors of avoidance and advocacy, and suggest that further research explore the potential impact these patient behaviors have on the provision of health care.

Ann Fam Med 2005;3:537-544. DOI: 10.1370/afm.346.

\section{INTRODUCTION}

M ost medical error research focuses on errors in hospital care, ${ }^{1}$ although most health care is delivered in the outpatient, primary care setting. ${ }^{2}$ Exactly what encompasses medical error and patient safety in the outpatient setting has been a matter of some debate..$^{3-5}$ Dovey and Phillips support a definition that includes "policy, regulation, payment and management as well as medical care delivery."4 The Institute of Medicine, in their report Patient Safety: Achieving a New Standard of Care, "strongly believes that patient safety is indistinguishable from the delivery of quality care." 6 Studies asking both patients and physicians to report or describe errors have produced responses as diverse as incorrect prescriptions, lost laboratory results, disrespectful physicians, and inability to get timely appointments. ${ }^{7,8}$

Even using a broad definition of patient safety that encompasses quality and related issues, there is still much we do not know about safety from the patient's point of view. ${ }^{8-11}$ Patients do report they experience error in ambulatory care, ${ }^{12,13}$ and many patients and physicians express the belief that patients have some responsibility for their safety. ${ }^{10}$ Several agencies and foundations recommend active patient involvement. ${ }^{14-17}$ Although no research indicates that following these recommendations will change patient outcomes, analogous studies of patient empowerment in dis-
Nancy C. Elder, MD, MSPH

Department of Family Medicine

University of Cincinnati

PO Box 670582

Cincinnati, OH 45267-0582

Eldernc@fammed.uc.edu 
ease management show that similar actions taken by patients do affect their outcomes. ${ }^{18-21}$

Anecdotal reports describe how patients who experience error change their behaviors in interacting with health care clinicians. ${ }^{9,22}$ Research supporting these reports or documenting the extent and type of these changes, however, has not been done. The purpose of this study was to assess how patients' experiences with self-perceived preventable problems, including medical error and quality lapses, affected them emotionally and altered their interactions with health care.

\section{METHODS}

This qualitative study was conducted between November 2002 and October 2003. Because of the exploratory nature of this research, we chose to use a solicitation question that was broad and put the onus of perception on the patient. Our question was similar to questions that have been used in other studies to identify patients who experienced medical error ${ }^{8}$ and is consistent with a broad definition of patient safety. ${ }^{6}$

The study was set in 2 large university-affiliated, community-based family practices in the Cincinnati, Ohio, area.

\section{Participant Selection}

After approval from our institutional review board, we obtained from practice databases a random sample of telephone numbers of patients stratified by age (younger than 18 years, 18 to 65 years, and older than 65 years) and race (white, not white [primarily African American]). We chose maximum variation based on demographic data because there were no existing data on which to otherwise define a selective sample. We began with more than 15,000 patients' telephone numbers and called patients from each stratified group until a respondent agreed to participate. We asked the person who answered (not necessarily the patient of record), "Have you or your child ever experienced a preventable problem with your primary care? Would you discuss it further with a researcher at a later time?" We continued calling patients, rotating through the stratified groups and soliciting participants, at the same time we were performing the interviews. When it became apparent that women were oversampled, we specifically asked to speak to men to maintain their representation. We assessed for data saturation through ongoing informal review of the interviews by the interviewer (NCE), a research assistant, and a medical anthropologist (CJJ). After 24 interviews, we believed patients were reporting no important new behaviors, and we stopped soliciting participants. To obtain these 24 interviews, we called 132 patients (Figure 1).

\section{Data Collection}

Participants were interviewed in their homes or workplace by 1 investigator (NCE). She introduced herself as a physician researcher from the university. In the semistructured interviews, she asked participants to tell her (1) their stories of preventable problems, (2) why they thought it happened, (3) what they could have done to prevent it, (4) how they have changed how they interact with health care, and (5) what lessons they learned from the experience(s). The interview was developed from the medical literature ${ }^{8,23}$ with input from other patient safety researchers for face validity. She then asked for demographic data. The interviews lasted 15 to 45 minutes and were audiotaped and transcribed, with all identifying information removed. Although a brief analysis of the types of problems experienced is reported here for context, this article discusses the emotional and behavioral responses to experiencing these preventable problems.

\section{Data Analysis}

We performed our analysis in the editing style ${ }^{24,25}$ using QSR NVivo 2.0 (QSR International Pty Ltd, Doncaster, Victoria, Aust). In this method, while acknowledging our previous assumptions, we sorted the interview data into coding categories derived from the data, explicitly

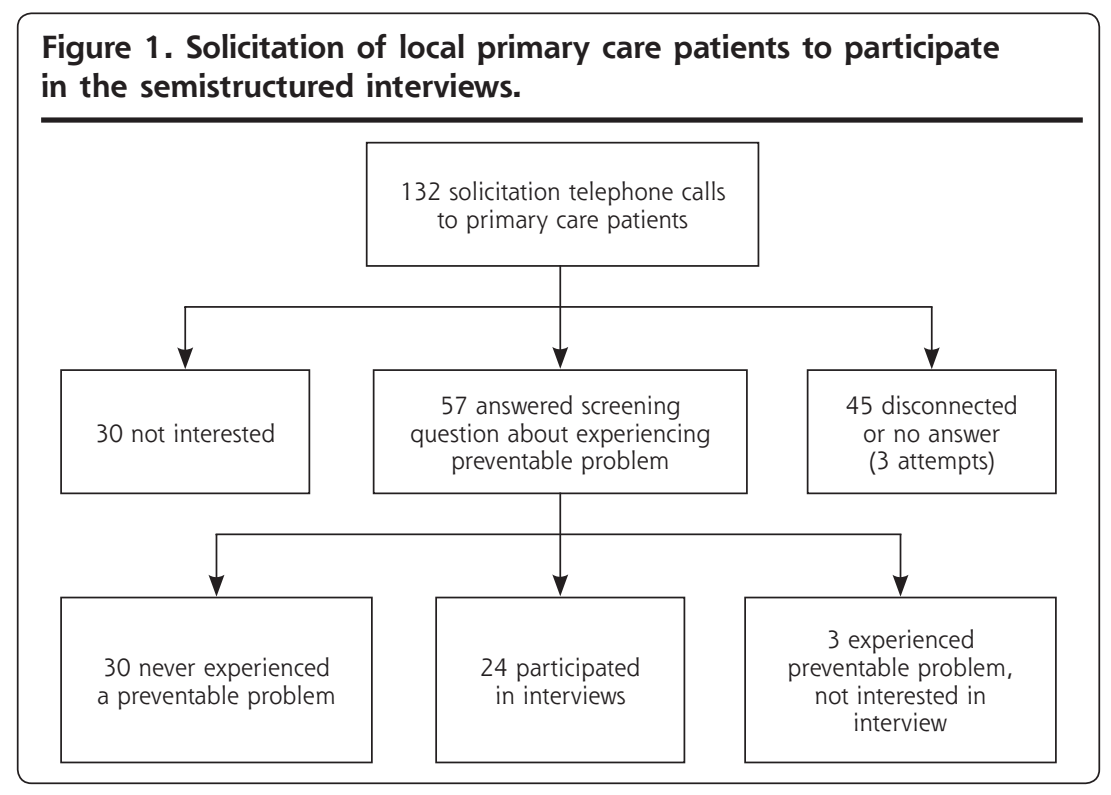


checking them against other categories and the original data, and then searched for patterns and themes.

Four researchers who had expertise in primary care (2 family physicians [NCE, TZ] in the same department, but in different clinical practices), sociology (LH), and medical anthropology (CJJ) provided a diverse team approach to the data. After all researchers reviewed and discussed 1 transcript, the senior author and 1 researcher read 12 transcripts and devised the initial coding categories, which were modified and then confirmed by all 4

\begin{tabular}{|lcl|}
\hline \multicolumn{2}{l}{ Table 1. Participant Characteristics } \\
\hline Characteristic & Number & Percent \\
\hline Sex & 18 & 75 \\
$\quad$ Women & 6 & 25 \\
$\quad$ Men & & \\
Race & 12 & 50 \\
$\quad$ White & 12 & 50 \\
African American & 51.5 & \\
Age, mean years & (range $20-81)$ & \\
Education & 3 & 12.5 \\
$\quad$ Less than high school graduate & 3 & 50 \\
High school graduate & 12 & 12.5 \\
Some college & 3 & 25 \\
College graduate or higher & 6 & \\
\hline
\end{tabular}

researchers. Each transcript was then read and coded by the senior author and an additional researcher. During coding, categories were added or modified, as needed, as we drew on the original transcripts for meaningful segments of text. ${ }^{24}$ During dyad meetings each interview was discussed until consensus in coding was reached. Then, in a series of meetings, all the researchers reread and discussed the coding categories and the original data and developed themes and models related to emotional and behavioral responses in the face of experiencing preventable problems and errors.

\section{RESULTS}

\section{Participants}

Table 1 displays the demographic characteristics of our 24 participants. Most (75\%) were women, and their ages ranged from 20 to 81 years. The participants were equally divided between African American and white.

\section{Types of Preventable Problems Experienced}

The 24 participants described experiencing 63 different preventable problems and errors, ranging from misdiagnosis to the inability to get a timely appointment (Table 2). Office administration and communication problems were most frequently described. Nine participants reported experiencing 2 problems; 10 participants experienced 3 or more problems.

\begin{tabular}{|c|c|c|}
\hline Main Problem & $\begin{array}{l}\text { Number } \\
\text { Reporting } \\
\text { Problem* }\end{array}$ & Examples \\
\hline \multicolumn{3}{|l|}{ Communication } \\
\hline Physician to patient & 15 & $\begin{array}{l}\text { Rude; lack of empathy; insufficient time } \\
\text { spent with patient; refusal to refer to } \\
\text { specialist }\end{array}$ \\
\hline With insurance company & 4 & $\begin{array}{l}\text { Wrong diagnosis sent to insurer; rude and } \\
\text { unhelpful }\end{array}$ \\
\hline Between physicians & 1 & $\begin{array}{l}\text { Miscommunication between physician and } \\
\text { anesthesiologist }\end{array}$ \\
\hline \multicolumn{3}{|l|}{ Office administration } \\
\hline Telephone problems & 5 & $\begin{array}{l}\text { Messages not relayed; unable to speak to } \\
\text { nurse or doctor on telephone }\end{array}$ \\
\hline Access and appointments & 10 & $\begin{array}{l}\text { Long waits in waiting room; appointments } \\
\text { cancelled without notice; incorrect } \\
\text { appointment times given }\end{array}$ \\
\hline Office staff & 6 & Rude; unhelpful; refusal to relay messages \\
\hline Office systems & 4 & $\begin{array}{l}\text { Lost laboratory sample; medical records lost; } \\
\text { inflexible in policies }\end{array}$ \\
\hline \multicolumn{3}{|l|}{ Clinical care } \\
\hline Missed diagnosis & 4 & $\begin{array}{l}\text { Deep vein thrombosis; otitis media; scoliosis; } \\
\text { reflux disease. }\end{array}$ \\
\hline Medication problems & 7 & $\begin{array}{l}\text { Dose cut in half; wrong drug prescribed or } \\
\text { dispensed }\end{array}$ \\
\hline $\begin{array}{l}\text { Procedural and equipment } \\
\text { problems }\end{array}$ & 4 & $\begin{array}{l}\text { Broken equipment; intravenous line left in } \\
\text { too long }\end{array}$ \\
\hline Lack of knowledge or skills & 3 & Blood pressure not taken; no therapy ordered \\
\hline Total & 63 & \\
\hline
\end{tabular}

\section{Emotional Responses}

The most common emotional response to experiencing preventable problems was anger; we frequently heard such statements as, "I was very, very disturbed," and "I ain't never been so mad before." Mistrust was also commonly expressed, as expressed by, "... it's hard to have faith anymore" in medicine, and "I am sort of distrustful of new doctors." A sense of resignation, that "it hasn't made any difference" or "I just let it go" was also common, but fear was mentioned only rarely.

\section{Behavioral Responses}

Participants expressed a number of behavioral responses to the problems they experienced. We classified these into 4 groups: avoidance, accommodation, anticipation and advocacy (Table 3 ). 
Individual participants usually used several behaviors, depending on the specific situation. Although many responded with several behaviors within a category, or even from 2 or 3 categories, only rarely did a participant responded with behaviors from every category.

\section{Table 3. Behavioral Responses to Experiencing Perceived Medical Problems}

\begin{tabular}{|c|c|c|}
\hline $\begin{array}{l}\text { Main Response } \\
\text { Category and } \\
\text { Subcategory }\end{array}$ & Type of Response & $\begin{array}{l}\text { Number } \\
\text { of Reports }\end{array}$ \\
\hline \multicolumn{3}{|l|}{ Avoidance } \\
\hline Total avoidance & Avoid or stop going to doctors & 7 \\
\hline \multirow{5}{*}{$\begin{array}{l}\text { Bypass parts of } \\
\text { health care }\end{array}$} & Change to another doctor's office & 12 \\
\hline & Bypass front office staff & 4 \\
\hline & Avoid phoning the doctor's office & 3 \\
\hline & Avoid teaching hospitals - residents & 3 \\
\hline & Go in person to make appointments & 1 \\
\hline \multirow[t]{5}{*}{ Accommodation } & Make no changes & 8 \\
\hline & Keep going to a doctor and follow advice & 3 \\
\hline & Learn to deal with waits and delays & 2 \\
\hline & Be cooperative, not demanding & 1 \\
\hline & Be timely for appointments & 1 \\
\hline \multicolumn{3}{|l|}{ Anticipation } \\
\hline \multirow[t]{9}{*}{ Attend to details } & $\begin{array}{l}\text { Schedule best appointment times and confirm } \\
\text { appointments }\end{array}$ & 10 \\
\hline & Document problems with staff & 7 \\
\hline & $\begin{array}{l}\text { Bring a list of medications and problems to } \\
\text { the doctor }\end{array}$ & 4 \\
\hline & $\begin{array}{l}\text { Write down medical information and questions } \\
\text { before going to the doctor }\end{array}$ & 4 \\
\hline & Do everything possible before going to the doctor & 3 \\
\hline & Be attentive to ones own medical record & 3 \\
\hline & Observe doctor's office and doctor closely & 2 \\
\hline & Check medications before taking them & 2 \\
\hline & $\begin{array}{l}\text { When waiting to be seen at office, ask how long } \\
\text { the wait will be }\end{array}$ & 1 \\
\hline \multirow{3}{*}{$\begin{array}{l}\text { Attend to own } \\
\text { emotions }\end{array}$} & Trust gut instincts & 5 \\
\hline & Only see a doctor you trust & 2 \\
\hline & Stay calm & 1 \\
\hline \multirow[t]{4}{*}{ Acquire knowledge } & $\begin{array}{l}\text { Educate self about medical condition, medications, } \\
\text { insurance }\end{array}$ & 18 \\
\hline & Check out doctor beforehand & 6 \\
\hline & Consult family or friends in health care & 4 \\
\hline & Check out hospital or emergency center & 1 \\
\hline \multirow{6}{*}{$\begin{array}{l}\text { Actively } \\
\text { communicate }\end{array}$} & Ask questions of the doctor & 11 \\
\hline & $\begin{array}{l}\text { Give more information about medical condition } \\
\text { to doctor }\end{array}$ & 8 \\
\hline & Be assertive with office staff & 8 \\
\hline & $\begin{array}{l}\text { Make sure you get heard by doctors and health } \\
\text { care workers }\end{array}$ & 5 \\
\hline & Tell doctor what you expect and want from visit & 5 \\
\hline & Tell the physician about system and staff problems & 3 \\
\hline \multirow[t]{6}{*}{ Advocacy } & Be a self-advocate & 12 \\
\hline & Bring or be an advocate for others & 8 \\
\hline & Get a second opinion & 4 \\
\hline & Explain why you changed doctors & 2 \\
\hline & Be willing to fight & 1 \\
\hline & Be a policy-level advocate & 1 \\
\hline
\end{tabular}

Avoidance

Avoidance includes both a partial or total avoidance of the system. Responses included the following:

"I don't interact (with doctors). I haven't been back since" (44-year-old white man; physician-insurance company communication problem).

"I just don't like to really be in the presence of doctors. I mean, like if I really don't have to, I will just try to deal with what I have to deal with outside of them instead of going to the doctor" (27-year-old African American woman; nursing mistake and doctor-patient communication problem).

Others tried to navigate around the parts of the system where the problems occurred, such as avoiding the telephone or the office staff. Some avoided their current doctor, office, or hospital by switching to another one.

\section{Accommodation}

Accommodation includes behaviors by participants who simply put up with problems and often changed their own behaviors to adjust to the system. For example, long waits to be seen were dealt with by "bringing things for the kids to do-and lots of snacks, too." Others believed that simply following the doctor's advice closely was the best thing to do:

"Follow the doctor's advice, he has been educated and he knows more about what to do than you do" (72-year-old white woman; procedural problem and doctor-patient communication problem).

Others just tolerated the mistakes: "I think it's just one of those things that happened" (81-year-old white woman; medication problem).

\section{Anticipation}

Anticipation involves foreseeing problems and acting or reacting to them. This category of responses was the largest, and we subdivided it into attend to details, attend to emotions, acquire knowledge, and actively communicate.

Attending to details includes 
keeping track of and asking for the best appointment times, as well as paying attention to medicines and dosages, keeping a list of medicines and health problems, and even double-checking the prescription at the pharmacy:

"People should always read before they pop a pill in their mouth, they should always make sure it's what they want" (34-year-old white man; medication problem).

Attending to emotions and paying attention to gut instinct were identified by many as important:

"Until basically somebody can tell you what you believe in your heart to be right, you just have to keep going" (42-year-old white woman; missed diagnosis and doctor-patient communication problem).

Acquiring knowledge includes consulting family, friends, books, and the Internet:

"Personally, things I do, I try to read books to see what is said. The children have computers, so I have them to look up something for me on the computer" (69-year-old African American woman; appointment problem).

Participants also stressed checking out a doctor ahead of time and using intelligent criteria to select a doctor.

Actively communicating with physicians and staff consists of giving a complete history, asking the doctor questions, and being assertive with the staff:

"I'm not afraid to ask any question about anything ... whatever procedure that is going to be done ${ }_{i}$ how it works. I know everything now. I'm not a bit shy anymore" (40-year-old white woman; office staff problems and doctor-insurance company communication problems).

Other participants pointed out the importance of communicating about expectations:

"I would say talk with your doctor and get more information... I need to get with [my new doctor] and talk more about what is expected of me and how much can I expect from him" (74-year-old African American man; office telephone problems).

\section{Advocacy}

Advocacy behaviors involve patients actively seeking better care for themselves and others. Some participants simply spoke up for themselves, insisting on a second opinion, while others had become policy advocates:

"I also belong to an organization; well, we are a little organization ... I have written to senators and congressmen" (72- year-old woman; broken equipment and doctor-patient communication problem).

Others focused on fighting for what they believed was right:

"I think first of all, you have to be assertive. I mean, you have to be firm. You can't go in there being meek.
I mean you want to be professional. You want to be kind, but you also want to get your point across" (55-year-old African American woman; office administration problem).

\section{Emotional and Behavioral Relationships}

As a qualitative study, our selection criteria for participation emphasized variability to achieve a wide range of responses to self-perceived preventable problems; we cannot quantify the types of responses by sex, age, or race. We did notice, however, that while anger and resignation were expressed by participants who used all types of behavioral responses, loss of trust was expressed most often by those who either avoid health care or use advocacy behaviors. For example, from a participant who generally avoids health care now:

"Sometimes I am kind of leery when I go. I am not as open as I was.... I go in now and just sort of watch them; before I would just go in and start talking" (44year-old African American woman; doctor-patient communication problem).

And from a participant who now describes himself as a partner in care:

"I guess there was a period of time where I just kind of trusted the doctor to take care of me. Now what I determine is that I need to really become a partner in that process and to pull from his knowledge and stay, as much as I can, aware of what my situation is so that I can ask the right questions" (68-year-old African American man; office staff and doctor-patient communication problem).

\section{DISCUSSION}

After experiencing challenges that ranged from seemingly interminable telephone waits for refills or results to rude physicians to serious misdiagnoses, our participants responded to preventable problems primarily with anger, although, not surprisingly, we also heard expressions of both mistrust and resignation. These feelings were translated into a variety of behaviors ranging from avoidance to advocacy. Understanding how patients react to their experiences with preventable problems can assist health care both at the physician-patient and system levels. We believe the 2 most important messages from our study are that (1) experiencing a preventable problem affects trust, resulting in an association of mistrust with health behaviors; and (2) patient behavior in response to these problems has a potential impact on the provision of health care.

It is not surprising the patients respond to medical errors and preventable problems with distrust in physicians and the health care system. In a study of attitudes toward error by patients anticipating brain surgery, the authors note that, "we asked patients about their feel- 
ings toward medical error, but by and large, they chose voluntarily to talk about trust." 26 Problems experienced in the ambulatory setting have been strongly related to lower trust in physicians, ${ }^{27}$ as have poor physician communication and perceived lack of honesty and caring. ${ }^{28,29}$ Trust has been seen as a mitigator of patients' level of concern about medical error ${ }_{1}^{26}$ so it is reasonable that when patients believe they have experienced error or problems that should be preventable, they will lose trust. We noted this lack of trust most often from participants who described avoidance and advocacy response behaviors (Figure 2). The medical literature confirms patients' use of avoidance behaviors when their trust is low, including voluntarily leaving a practice, reduced rates of care seeking, and less use of medications and treatments. ${ }^{28,30} \mathrm{~A}$ lack of trust associated with advocacy behaviors is not mentioned in the medical literature. This association needs to be explored further in future studies, as does a direct causal link between loss of trust and change in behaviors.

The range of steps made by our participants in the anticipation and advocacy categories echos many of the recommendations made by policy and patient safety experts. ${ }^{14-17} \mathrm{We}$ propose that these behaviors may have a greater impact than avoidance or accommodation behaviors on how health care is provided (Figure 3). Whereas both avoidance or accommodation are active-leaving a practice permanently is a big step for a patient - they may have little impact on a practice when done with no explanation. On the other hand, the behaviors of those who advocate for themselves or who have actively embraced self-education and communication may affect physicians and their practices. There is little in the medical literature on this topic. Organizational change is a complex process, and many models of change exist. ${ }^{31}$ Inherent to most of them, however, is the importance of having a tension for change, the belief that problems exist with current processes. Also important for change is an understanding of customers' (or in this case, patients') needs and concerns. ${ }^{31}$ Patients who actively advocate, educate, and communicate may be more likely to instill that tension and understanding in a practice or health care system. None of the current literature, however, appears to relate patient behaviors directly to changes in the practice of medicine. This possible connection needs to be better studied.

The only other published data on patients' behavior changes in response to experiencing error, a 1997 survey commissioned by the National Patient Safety Foundation, found that the 3 most common safety precautions these patients now take are asking questions; researching the hospital, physician, or treatment; and getting a second opinion. ${ }^{12}$ These responses are consistent with those reported by our participants. Participants in our study went beyond these recommendations and noted the importance of dealing with the office system-from choosing the best times for appointments to dealing with difficult staff. These areas are often overlooked by policy experts and are important in primary care. Research is needed, however, to know whether patients who use these behaviors will have safer or higher quality of care. Many of our participants expressed a belief that their new way of acting has changed the quality of their care, but corroborating research is sketchy. There is evidence that patients 
can learn to be more active participants in their health care. Experience in chronic disease management, ${ }^{21,32,33}$ treatment adherence, ${ }^{19,34}$ health promotion, ${ }^{35}$ and communication skills training ${ }^{36,37}$ suggests that patients can change their behaviors in specific areas. At times these changed behaviors have been shown to improve outcomes. ${ }^{18,21,36}$ Advancing from these specific areas to improvement in patient safety is a common assumption, but especially in the complex world of primary care, more empiric research is needed. ${ }^{38}$

Although this study offers a qualitative glimpse into how patients respond to preventable problems in their primary care, there are limitations. Our participants were self-selected, and their experiences might not be generalizable to other primary care populations. Participants included a greater proportion of women than men despite our active recruitment of men. We may have missed some behaviors that men were more likely to adopt. Participants were asked to discuss any preventable problems in their primary care, so their stories are likely to be recent or memorable incidents, not necessarily all incidents that they may have experienced. Interviews were semistructured, but not limited by any time restraints. While this one-time approach to each participant limited our ability to probe deeply into some issues, such as the relative importance of the problem experience, other medical experiences, and media publicity of medical errors in shaping emotional response and behavioral change, we did allow participants sufficient time to tell their story, probing for areas the literature suggested possibly important in response to error.

We elected to use a broad definition of patient safety, allowing patients to self-determine preventable problems, and we elicited stories and experiences that others may believe fall outside the realm of safety and errors. We believe this broad definition is consistent with the medical literature ${ }^{6-8,23}$ and allowed us to obtain a complete picture of how patients responded to all types of preventable problems. To paraphrase Kuzel and colleagues, ${ }^{8}$ whether the label of errors applies may be less important than recognizing the emotional and behavioral responses to preventable problems associated with primary health care.

Participants shared their responses to a variety of self-perceived preventable problems. Although anger was present, and trust was lost in physicians and health care, many participants still developed proactive behaviors to help them avoid or minimize preventable problems in the future. Future research is necessary to identify which behaviors commonly performed by patients really improve their safety, and whether patients can learn to adopt these behaviors before they ever experience problematic care.
To read or post commentaries in response to this article, see it online at http://www.annfammed.org/cgi/content/full/3/6/537.

Key words: Primary health care; professional-patient relations; patient safety; patients

Submitted January 20, 2005; submitted, revised, April 25, 2005: accepted May 16, 2005.

This work was a distinguished research presentation at the Annual Meeting of the Society for Teachers of Family Medicine, May, 2004.

Funding support: Grant number R03 HS1345201 from the US Agency for Healthcare Research and Quality.

\section{References}

1. Kohn L, Corrigan J, Donaldson M. To Err is Human: Building a Safer Health System. Washington, DC: National Academy Press; 1999.

2. Green LA, Fryer GE, Jr, Yawn BP, Lanier D, Dovey SM. The ecology of medical care revisited. N Engl J Med. 2001;344:2021-2025.

3. Woolf SH. Patient safety is not enough: targeting quality improvements to optimize the health of the population. Ann Intern Med. 2004;140:33-36.

4. Dovey SM, Phillips RL. What should we report to medical error reporting systems? Qual Saf Health Care. 2004;13:322-323.

5. Lee TH. A broader concept of medical errors. N Engl J Med. 2002;347:1965-1967.

6. Aspden P, Corrigan J, Wolcott J, Erickson S. Patient Safety: Achieving a New Standard of Care. Washington, DC: National Academies Press; 2004.

7. Dovey SM, Meyers DS, Phillips RL, Jr, et al. A preliminary taxonomy of medical errors in family practice. Qual Saf Health Care. 2002;11: 233-238.

8. Kuzel AJ, Woolf SH, Gilchrist VJ, et al. Patient reports of preventable problems and harms in primary health care. Ann Fam Med. 2004;2:333-340.

9. Goeltz R, Hatlie MJ. Trial and error in my quest to be a partner in my health care: a patient's story. Crit Care Nurs Clin North Am. 2002; 14:391-399.

10. Blendon RJ, DesRoches CM, Brodie M, et al. Views of practicing physicians and the public on medical errors. N Engl J Med. 2002;347:1933-1940.

11. Awe C, Lin SJ. A patient empowerment model to prevent medication errors. J Med Syst. 2003;27:503-517.

12. Public opinion of patient safety issues. Chicago, Ill: National Patient Safety Foundation; 1997.

13. Public Opinion and Media Research Program. Kaiser Family Foundation. National Survey on consumer's experiences with patient safety and quality information. 2004. Available at: http://www.kff.org/kaiserpolls/pomr111704pkg.cfm.

14. National Patient Safety Foundation. You can help improve patient safety. 2002. Available at: http://www.npsf.org/html/patients.html.

15. JCAHO. Speak up: Help prevent errors in your care. 2002. Available at: http:// www.jcaho.org/speakup_bro.html.

16. Agency for Healthcare Research and Quality. Patient fact sheet: 20 tips to help prevent medical errors. 2000. Available at: http://www. ahrq.gov/consumer/20tips.htm.

17. Partnership for Clear Health Communication. Ask Me 3. 2003. Available at: http://www.Askme3.org. 
18. McDonald HP, Garg AX, Haynes RB. Interventions to enhance patient adherence to medication prescriptions: scientific review. JAMA. 2002;288:2868-2879.

19. Haynes RB, McDonald HP, Garg AX. Helping patients follow prescribed treatment: clinical applications. JAMA. 2002;288:2880-2883.

20. Cegala DJ, Marinelli T, Post D. The effects of patient communication skills training on compliance. Arch Fam Med. 2000;9:57-64.

21. Norris SL, Engelgau MM, Narayan KM. Effectiveness of self-management training in type 2 diabetes: a systematic review of randomized controlled trials. Diabetes Care. 2001;24:561-587.

22. Gibson R, Singh JP. Wall of Silence: The Untold Story of the Medical Mistakes that Kill and Injure Millions of Americans. Washington, DC: Lifeline Press; 2003.

23. Elder NC, Dovey SM. Classification of medical errors and preventable adverse events in primary care: a synthesis of the literature. I Fam Pract. 2002; 51:927-932.

24. Miller M, Crabtree BF. Clinical research. A multimethod typology and qualitative roadmap. In: Crabtree BF, Miller M, eds. Doing Qualitative Research. 2nd Thousand Oaks, Calif: Sage Publications; 1999.

25. Miller WL, Crabtree BF. Qualitative analysis: how to begin making sense. Fam Pract Res J. 1994;14:289-297.

26. Bernstein M, Potvin D, Martin DK. A qualitative study of attitudes toward error in patients facing brain tumour surgery. Can J Neurol Sci. $2004 ; 31: 208-212$.

27. Keating NL, Green DC, Kao AC, et al. How are patients' specific ambulatory care experiences related to trust, satisfaction, and considering changing physicians? J Gen Intern Med. 2002;17:29-39.
28. Thom DH, Hall MA, Pawlson LG. Measuring patients' trust in physicians when assessing quality of care. Health Aff (Millwood). 2004;23:124-132.

29. Thom DH. Training physicians to increase patient trust. J Eval Clin Pract. 2000;6:245-253.

30. Safran DG, Montgomery JE, Chang H, Murphy J, Rogers WH. Switching doctors: predictors of voluntary disenrollment from a primary physician's practice. J Fam Pract. 2001;50:130-136.

31. Gustafson DH, Sainfort F, Eichler M, et al. Developing and testing a model to predict outcomes of organizational change. Health Serv Res. 2003;38:751-776.

32. Von Korff M, Gruman J, Schaefer J, Curry SJ, Wagner EH. Collaborative management of chronic illness. Ann Intern Med. 1997;127:1097-1102.

33. Wagner EH, Austin BT, Davis $\mathrm{C}$, et al. Improving chronic illness care: translating evidence into action. Health Aff (Millwood). 2001;20:64-78.

34. Hurme E, Pourciau CA. Preventing medication errors in the home. Geriatr Nurs. 2001;22:338-339.

35. Resnick B. Promoting health in older adults: a four-year analysis. J Am Acad Nurse Pract. 2001;13:23-33.

36. Cegala DJ, Post DM, McClure L. The effects of patient communication skills training on the discourse of older patients during a primary care interview. J Am Geriatr Soc. 2001;49:1505-1511.

37. Post DM, Cegala DJ, Miser WF. The other half of the whole: teaching patients to communicate with physicians. Fam Med. 2002;34:344-352.

38. Robinson JL, Nash DB. Consumers' role in patient safety. QRC Advis. $2000 ; 17: 1-3$ 